\title{
Cytotoxicity and genotoxicity of thymol verified in murine macrophages (RAW 264.7) after antimicrobial analysis in Candida albicans, Staphylococcus aureus, and Streptococcus mutans
}

\author{
Kely Karina Belato, Jonatas Rafael de Oliveira*, Fernanda Saraiva de Oliveira, \\ Luciane Dias de Oliveira, Samira Esteves Afonso Camargo
}

São Paulo State University (UNESP), Institute of Science and Technology, Department of Biosciences and Oral Diagnosis, Av. Engenheiro Francisco José Longo, 777 Jardim São Dimas, São José dos Campos, SP CEP 12245-000, Brazil

\section{A R T I C L E I N F O}

\section{Keywords:}

Thymol

Antimicrobial activity

Cytotoxicity

Genotoxicity

TNF- $\alpha$

\begin{abstract}
A B S T R A C T
Thymol is a phytocompound present in many plants and several biological effects have been reported, such as antimicrobial effect. However, the biocompatibility of this plant product should be checked. Thereby, the action of thymol was evaluated in C. albicans, S. aureus, and S. mutans, as well as in murine macrophages (RAW 264.7). Firstly, the effect of thymol was analyzed in planktonic cultures of microorganisms and the most effective concentration was evaluated in biofilms. Cytotoxicity, quantification of TNF- $\alpha$ and genotoxicity were checked. The results were analyzed by T-Test or ANOVA and Tukey's Test $(P \leq .05)$. Thymol provided inhibitory and microbicidal effects for planktonic cultures and reduction of biofilms. High concentrations affected the viability of RAW 264.7. Production of TNF- $\alpha$ and frequency of micronuclei were similar to the control group. Thus, thymol showed antimicrobial effect, biocompatibility in some concentrations and absence of genotoxicity.
\end{abstract}

\section{Introduction}

The increasing demand for novel antimicrobial agents has provided investigations about the effect of phytocompounds from plant species on microorganisms due to incidence of side effects to usual medicines, as well as the resistance to available antibiotics (Sharifzadeh, Khosravi, Shokri, \& Sharafi, 2015). These phytocompounds are abundantly present in essential oils and their antimicrobial effect has been investigated due action on several species of bacteria and fungi (Filoche, Soma, \& Sissons, 2005) and the plant products provides a low risk of microbial resistance (Veras et al., 2012).

Thymol is a phytocompound present in essential oil of many plants and it can act on the cell membrane, impairing the permeability of substances. In addition, it can cause denaturation of enzymes and modification of proton driving forces, due to changes in $\mathrm{pH}$ and electric potential. On the other hand, it can improve the intake of antibiotics (Stammati et al., 1999).

The antimicrobial effect of thymol has been related, with capability to make permeable and depolarized the cell membrane of microorganisms (Gutiérrez, Batlle, Sánchez, \& Nerín, 2010). This action has been demonstrated on several species, being considered an agent with effect of broad spectrum (Burris, Davidson, Stewart, \& Harte, 2011), including S. mutans, Lactobacillus plantarum, Candida spp. (Faria et al., 2011; Guo et al., 2009; Gutiérrez et al., 2010), viruses and protozoa (Gaysinsky, Taylor, Davidson, Bruce, \& Weiss, 2007). Some effects have been reported, such as inhibitory on the development of biofilm of $S$. aureus and prevention of formation of dental caries (de Castro et al., 2015; Rúa et al., 2010). Additionally, other biological activities have also been cited as antioxidant, anticarcinogenic, anti-inflammatory and gastroprotective (Braga et al., 2005; Gutiérrez et al., 2010; Jentsch, Eckert, Eschrich, Stratul, \& Kneist, 2014).

C. albicans is the most prevalent fungus in the human oral cavity and it is related to cases of stomatitis in patients with dental prostheses (Dalleau, Cateau, Bergès, Berjeaud, \& Imbert, 2008). As an inhabitant of various parts of the body, it can opportunely cause superficial candidiasis and even systemic infections (de Vasconcelos, Sampaio, de Albuquerque, \& Vasconcelos, 2014; Seneviratne, Wang, Jin, Abiko, \& Samaranayake, 2010). Over the last decades, the occurrence of infections by $C$. albicans has increased, mainly in immunocompromised patients (Bürgers, Witecy, Hahnel, \& Gosau, 2012). The biofilm of C. albicans consists of a dense network of yeasts, hyphae and pseudohyphae wrapped in a self-produced matrix composed of polymeric material that

\footnotetext{
* Corresponding author.

E-mail addresses: kely_k@msn.com (K.K. Belato), jroliveira16@hotmail.com (J.R. de Oliveira), fernandalima.odonto@hotmail.com (F.S. de Oliveira), luciane@ict.unesp.br (L.D. de Oliveira), samira@ict.unesp.br (S.E.A. Camargo).
} 
contributes to adhesion to the substrate and proliferation of yeast cells (de Vasconcelos et al., 2014). The ability of $C$. albicans to form biofilm is of clinical interest, since these communities are more resistant to action of antifungal agents and host's natural defenses (Fu et al., 2014).

$S$. aureus can be considered a pathogenic agent related to hospital infections and as an important problem of Public Health (de Oliveira, Stamford, Gomes Neto, \& de Souza, 2010). It is also known to cause food poisoning due to production of toxic extracellular compounds (Pereira et al., 2009), such as staphylococcal enterotoxins that cause vomiting and diarrhea when ingested (Fratini et al., 2014). S. aureus is responsible for other clinical manifestations, including skin diseases, soft tissue injuries, osteomyelitis, endocarditis, pneumonia and septicemia (Qiu et al., 2010). The elimination this bacterium is difficult, since antibiotic-resistant strains constantly appear (Koziel et al., 2008).

$S$. mutans is one of the pathogens that cause dental caries, being responsible for induction of mineral loss, due to strong adherence to dental surface, demineralization of hydroxyapatite and generation of acids from the degradation of fermentable carbohydrates of the host's diet. Therefore, the control of caries may be favored with the reduction of levels of this microorganism in the oral cavity (Paula, Modesto, Santos, \& Gleiser, 2010).

The use of products extracted from medicinal plants, such as phytocompounds, may be one alternative strategy to control microorganisms due to effectiveness and biocompatibility presented for these products. In this way, this study evaluated the action of thymol in $C$. albicans, $S$. aureus, and $S$. mutans, both in planktonic cultures and biofilms. Additionally, cytotoxic and genotoxic effects were also verified in murine macrophages (RAW 264.7).

\section{Material de methods}

\subsection{Plant product}

Thymol (2-isopropyl-5-methylphenol $-\mathrm{C}_{10} \mathrm{H}_{14} \mathrm{O}$ ) was commercially acquired at $\geq 99.5 \%$ (Sigma-Aldrich, St, Louis, USA). A stock solution was prepared in dimethyl sulfoxide (DMSO - Sigma-Aldrich) at $4.26 \mathrm{mmol} / \mathrm{L}$ and this solution was filtered in a membrane of $0.22 \mu \mathrm{m}$ (TPP, Trasadingen, Switzerland). The action of the solvent was also analyzed in all the tests to check its possible interference on microorganisms and cells.

\subsection{Microbial strains}

Reference strains (ATCC - American Type Culture Collection) of $C$. albicans (ATCC 18804), S. aureus (ATCC 6538) and S. mutans (ATCC 35688) from the Institute of Science and Technology (ICT/UNESP) were used. The samples were stored at $-80^{\circ} \mathrm{C}$ in specific medium, such as Yeast Extract Peptone Dextrose broth (YPD - Himedia, Mumbai, India) with $16 \%$ glycerol, for $C$. albicans, and Brain Heart Infusion broth (BHI - Himedia) with $20 \%$ glycerol, for bacteria. The reactivation of the samples was performed on Sabouraud dextrose agar (SD - Himedia) or BHI agar (Himedia), respectively, for $24 \mathrm{~h}$ at $37^{\circ} \mathrm{C}$. S. mutans was incubated in $5 \% \mathrm{CO}_{2}$.

\subsection{Antimicrobial activity on planktonic cultures}

Broth microdilution method was used according to Clinical and Laboratory Standards Institute (CLSI), M7-A6 (CLSI, 2003), M27-A2 (CLSI, 2002) e M27-S4 (CLSI, 2012) protocols. After reactivation of the microorganisms, colonies were suspended in sterile saline solution $(0.9 \% \mathrm{NaCl})$ with turbidity adjusted to $10^{6} \mathrm{CFU} / \mathrm{mL}$ (colony-forming units per milliliter) in a spectrophotometer (Micronal, SãoPaulo, Brazil) using the parameters of $530 \mathrm{~nm}$ and optical density (OD) of $0.284 \pm 0.02$ for C. albicans, $490 \mathrm{~nm}$ and $0.374 \pm 0.02$ for $S$. aureus and $398 \mathrm{~nm}$ e $0.620 \pm 0.02$ for $S$. mutans. For $C$. albicans, from the suspension of $10^{6} \mathrm{CFU} / \mathrm{mL}$, two dilutions were performed, being one of
1:50 and other of 1:20 in culture medium. In microplate (TPP, Trasadingen, Switzerland), $100 \mu \mathrm{L}$ of medium were added in each well, being RPMI 1640 with glutamine, without bicarbonate and phenol red indicator (Himedia) buffered with MOPS [3- (N-morpholino) propanesulfonic acid] (Sigma-Aldrich, St. Louis, USA) at pH 7.0 \pm 0.1 , for $C$. albicans, and Mueller Hinton both (Himedia), for bacteria. Then, $100 \mu \mathrm{L}$ of thymol were added only in the first well, where a series of ten dilutions of this phytocompound was started. On the solutions, $100 \mu \mathrm{L}$ of microbial suspension were added. Thereby, the evaluated concentrations of thymol ranged from 1.06 to $0.002 \mathrm{mmol} / \mathrm{L}$. The concentrations of inocula were from $5 \times 10^{2}$ to $2.5 \times 10^{3} \mathrm{CFU} / \mathrm{mL}$, for C. albicans, and $5 \times 10^{5} \mathrm{CFU} / \mathrm{mL}$, for bacteria. After $24 \mathrm{~h}$ of incubation, the minimum inhibitory concentration (MIC) of the thymol was determined in the lowest concentration with visual absence of turbidity. Posteriorly, $100 \mu \mathrm{L}$ of MIC and adjacent concentrations were added on SD or BHI agar and, after $48 \mathrm{~h}$ of incubation, the lower concentration of thymol capable of causing total absence of colony growth was determined as minimum microbicidal concentration (MMC), which included the minimum fungicidal concentration (MFC) and minimum bactericidal concentration (MBC).

\subsection{Antimicrobial activity on biofilms}

This analysis was performed according to Oliveira et al. (2017). After reactivation of the microorganisms, C. albicans was cultured in Yeast Nitrogen Base broth (YNB - Himedia) and bacteria in BHI both for $24 \mathrm{~h}$ at $37^{\circ} \mathrm{C}$. Suspensions were centrifuged at $358 \mathrm{~g}$ (MPW-350, Warsaw, Poland), supernatant was discarded and pellet was suspended in saline solution, this process was performed twice. After, the microbial suspensions were standardized in a spectrophotometer at $10^{7} \mathrm{CFU} /$ $\mathrm{mL}$, using the same wavelengths, however the OD were of $0.381 \pm 0.02$ (C. albicans), $0.447 \pm 0.02$ (S. aureus) e $0.560 \pm 0.02$ (S. mutans). Each suspension was separately distributed in wells of microtiter plate $\left(200 \mu \mathrm{L} /\right.$ well) and incubation $\left(37^{\circ} \mathrm{C}\right)$ under agitation (Quimis, Diadema, Brasil) was performed for $90 \mathrm{~min}$ for pre-adhesion of the biofilms. Then, the supernatant was replaced with YNB or BHI broth and the biofilms were formed for $48 \mathrm{~h}$ with replacement of medium after $24 \mathrm{~h}$ of incubation. Posteriorly, the biofilms were exposed to highest MIC of thymol for 5 min and saline solution was used as control ( $n=10$ /group). Two washes with saline were performed to eliminate the affected microbial cells and then the biofilms were disaggregated for $30 \mathrm{~s}$ and $25 \%$ power by ultrasonic homogenizer (Sonopuls HD 2200 - Bandelin Eletronic, Berlin, Germany). Suspensions were diluted and added on SD or BHI agar. After $48 \mathrm{~h}$ of incubation, the concentration of $\mathrm{CFU} / \mathrm{mL}$ obtained in the experimental groups was determined and the values were presented in $\log _{10}$.

\subsection{Cell culture}

Murine macrophages (RAW 264.7) obtained from the Rio de Janeiro Cell Bank (APABCAM, Rio de Janeiro, Brazil) were cultured in Dulbecco's modified Eagle medium (DMEM - LGC, Cotia, Brazil) with $10 \%$ fetal bovine serum (Invitrogen, New York, USA) and 1\% penicillinstreptomycin (Gibco, Grand Island, USA) at $37^{\circ} \mathrm{C}$ and $5 \% \mathrm{CO}_{2}$ with atmospheric humidity. After subconfluency, a count of viable cell was performed by Trypan blue (0.4\% - Sigma-Aldrich).

\subsection{Cytotoxicity by MTT assay}

This analysis was performed according to Oliveira et al. (2017). In microplate, $200 \mu \mathrm{L}$ of DMEM containing $4 \times 10^{4}$ viable cells were added in each well. After $24 \mathrm{~h}$ of incubation, the wells were washed with phosphate buffered saline (PBS - LGC) and $200 \mu \mathrm{L}$ of DMEM with thymol $(1.06-0.002 \mathrm{mmol} / \mathrm{L})$ or pure DMEM $(0 \mathrm{mmol} / \mathrm{L})$ were added on the cells ( $n=10 /$ group). After $24 \mathrm{~h}$ of exposure, the wells were washed with PBS to discard non-viable cells and solution of MTT [(3- 
4,5 dimetiltiazol-2il-2,5-difenil-tetrazólio), Sigma-Aldrich] at $0.5 \mathrm{mg} /$ $\mathrm{mL}$ of PBS was added (100 $\mu \mathrm{L} /$ well). An incubation for $1 \mathrm{~h}$ was performed under light protection and then the supernatant was replaced with DMSO (100 $\mu \mathrm{L} /$ well). After a new incubation $(10 \mathrm{~min})$ and shaking $(10 \mathrm{~min})$, the microplate was read in a spectrophotometer (Bio-Tek, Vermont, USA) at $570 \mathrm{~nm}$ and the OD were converted to percentage of cell viability, in relation to the control group.

\subsection{Quantification of TNF- $\alpha$}

The production of TNF- $\alpha$ by the macrophages was performed on cells cultured for $24 \mathrm{~h}$ in 24-well plate. For this end, $1000 \mu \mathrm{L}$ of DMEM containing $5 \times 10^{5}$ viable cells were added in each well. The supernatant was discarded and $1000 \mu \mathrm{L}$ of DMEM with thymol in less damaging concentrations for the macrophages or pure DMEM were added, being $n=10 /$ group. After $24 \mathrm{~h}$ of exposure, these supernatants were collected and stored at $-20^{\circ} \mathrm{C}$ for posterior quantification of TNF- $\alpha$ by ELISA. Therefore, a commercial kit was used ( $\mathrm{R} \& \mathrm{D}$ Systems, DY410 catalog, Minneapolis, USA), according to the manufacturer's guidance. The OD obtained at $450 \mathrm{~nm}$ in a spectrophotometer were converted in picograms per milliliter $(\mathrm{pg} / \mathrm{mL})$, considering the standard curve of TNF- $\alpha$, using GraphPad Prism 5.0 software for this.

\subsection{Genotoxicity by micronucleus test}

This analysis was performed according to Camargo et al. (2009). On sterile glass slides in sterile polystyrene chamber with four compartments (Nunc, Roskilde, Denmark) $4000 \mu \mathrm{L}$ of DMEM containing $3 \times 10^{5}$ viable cells were added. After $24 \mathrm{~h}$ of incubation, the supernatant was replaced with DMEM containing thymol in less damaging concentrations for the macrophages or pure DMEM and ethyl methanesulfonate (EMS - Sigma-Aldrich) was used as positive control, being $n=2$ /group. Posteriorly, the slides were washed with buffered saline (free of calcium and magnesium) and the cells were fixed with $100 \%$ ethanol (30 min) and lysed with $5 \mathrm{~N} \mathrm{HCl}(40 \mathrm{~min})$. After washing with deionized water, the cells were stained with SCHIFF (Sigma-Aldrich) for $30 \mathrm{~min}$ at room temperature. Then, the slides were washed in solution of sulfate for $6 \mathrm{~min}$ and in running water for $10 \mathrm{~min}$. After dehydration of cells, the slides were mounted with Entellan (Merck, Darmstadt, Germany) and they were analyzed in optical microscope with immersion lens $(1000 \times)$. Micronuclei frequency was verified in 1000 cells/ slide in each experimental group. Therefore, the micronuclei were identified as structures of DNA present in the cytoplasm, separated from the main nucleus and close of it, measuring about $1 / 3$ of the nucleus (Fig. 4A).

\subsection{Statistical analysis}

Data were presented in mean values ( \pm standard deviation) and analyzed statistically by T-Test or ANOVA and Tukey's Test with statistical significance when $P \leq .05$. For this purpose, GraphPad Prism 5.0 software was used.

\section{Results}

The action of thymol in C. albicans, S. aureus, and $S$. mutans can be verified in Table 1, with presentation of MIC and MMC for each microorganism. In addition, the highest MIC of this phytocompound $(1.06 \mathrm{mmol} / \mathrm{L})$ was tested in biofilms of these species and significant reductions of $\mathrm{CFU} / \mathrm{mL}$ were verified after treatment with the plant product (Fig. 1).

Analyzing the cell viability of the macrophages, similar percentages to the control group (100) were found in groups treated with concentrations of $0.004(100), 0.008(111 \pm 12)$ and $0.017 \mathrm{mmol} / \mathrm{L}$ $(114 \pm 13)$. However, a significant decrease in the cell viability was observed in relation to the control group after contact with
Table 1

Antimicrobial action of thymol on planktonic cultures of $C$. albicans, $S$. aureus, and $S$. mutans.

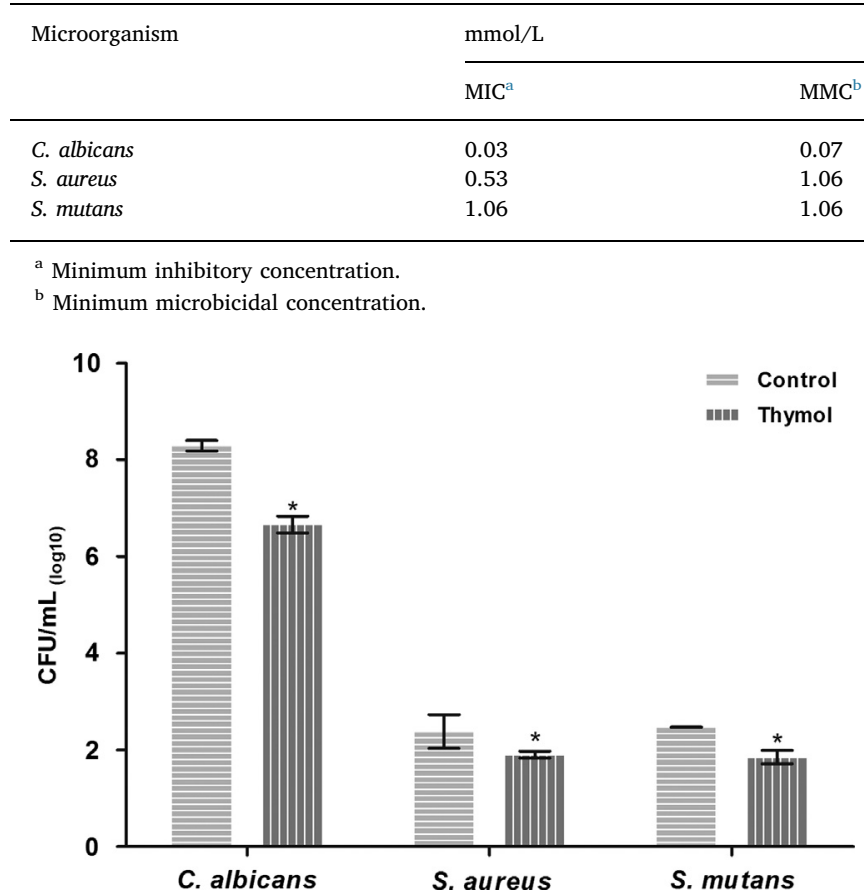

Fig. 1. Antibiofilm activity of thymol analyzed on C. albicans, S. aureus, and S. mutans. "Significant reduction of $\mathrm{CFU} / \mathrm{mL}\left(\log _{10}\right)$ presented after exposure to the phytocompound $(1.06 \mathrm{mmol} / \mathrm{L})$ in relation to the control group $(0.9 \% \mathrm{NaCl}$ solution) $(n=10$; T-Test; $P \leq .05)$.

concentrations of $0.002(72 \pm 12), 0.03(74 \pm 9), 0.07(4 \pm 3), 0.13$ (4 \pm 6$), 0.27$ ( $4 \pm 4), 0.53$ (4) and $1.06 \mathrm{mmol} / \mathrm{L}(12 \pm 2)$, as demonstrated in Fig. 2C.

Thymol stimulated the synthesis of TNF- $\alpha(\mathrm{pg} / \mathrm{mL})$ in more viable concentrations for the macrophages, however, its level were similar to the control group ( $9 \pm 7$ ) after contact with concentrations of 0.002 $(26 \pm 11), 0.004(23 \pm 11), 0.008(16 \pm 15)$ and $0.017 \mathrm{mmol} / \mathrm{L}$ $(6 \pm 11)$, as shown in Fig. 3 .

The evaluated concentrations presented no genotoxic effect for the macrophages, since the frequency of micronuclei presented for the groups treated with concentrations of $0.002(24 \pm 5), 0.004(22 \pm 6)$, $0.008(29 \pm 4)$, and $0.017 \mathrm{mmol} / \mathrm{L}(27 \pm 5)$ was similar to the control group $(23 \pm 4)$ and different to the genotoxic agent (EMS, positive control), which presented a frequency of $60 \pm 4$ micronuclei, as demonstrated in Fig. 4.

In addition, the solvent (DMSO) used in the preparation of the stock solution of thymol presented no interference in the tests performed on microorganisms and cells.

\section{Discussion}

In this study, thymol presented a significant effect in relation to the control of $C$. albicans, $S$. aureus, and $S$. mutans, demonstrating both inhibitory and microbicidal capacity on planktonic cultures (Table 1). Among the evaluated strains, $C$. albicans was the most sensitive to the phytocompound, since on the yeast, thymol provided the lowest MIC $(0.03 \mathrm{mmol} / \mathrm{L})$ and $\mathrm{MMC}(0.07 \mathrm{mmol} / \mathrm{L})$, compared to $S$. aureus $(\mathrm{MIC}=0.53 \mathrm{mmol} / \mathrm{L} ; \mathrm{MMC}=1.06 \mathrm{mmol} / \mathrm{L})$ and $S$. mutans $(\mathrm{MIC}$ and MMC $=1.06 \mathrm{mmol} / \mathrm{L}$ ). The antimicrobial effect of thymol is related to its ability to interact with components of the cell membrane of bacteria and fungi (Helander et al., 1998; La Storia et al., 2011). This phytocompound also has the ability to permeabilize and depolarize the cytoplasmic membrane (Hammer \& Heel, 2012). Thymol crosses the cell 

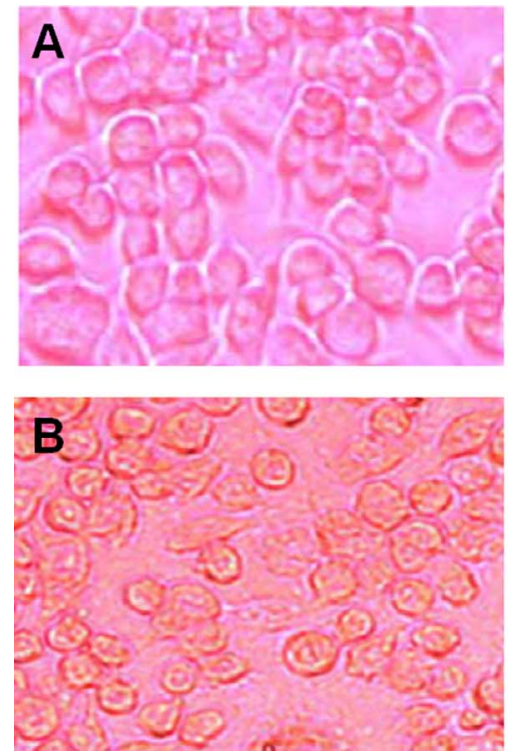

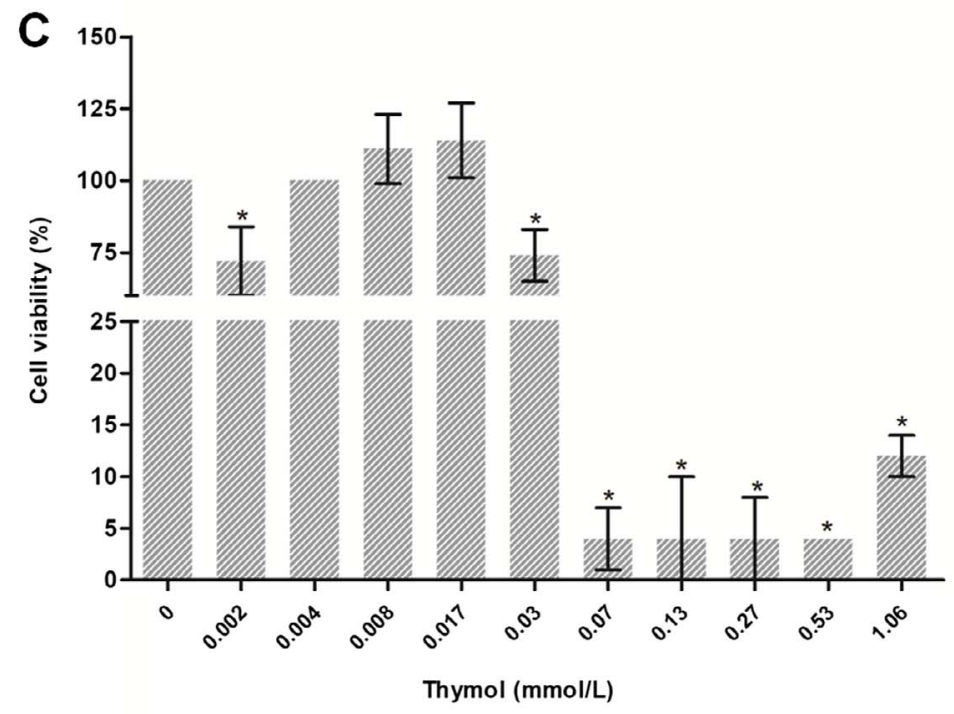

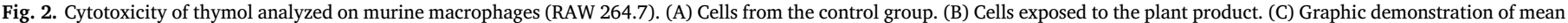

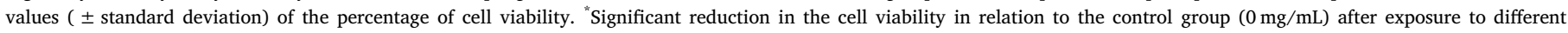
concentrations of phytocompound ( $n=10$; ANOVA and Tukey's Test; $P \leq .05$ ).

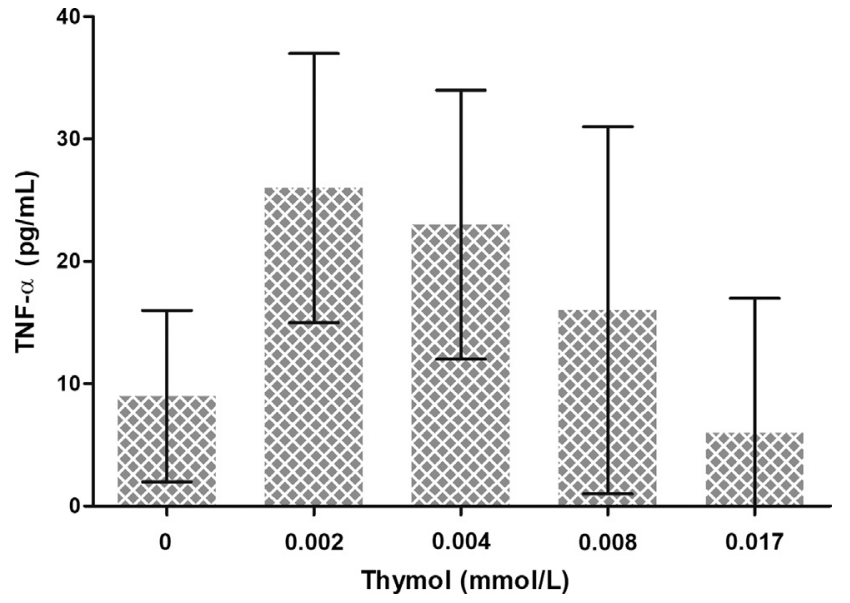

Fig. 3. Production of TNF- $\alpha$ by murine macrophages (RAW 264.7) after exposure to different concentrations of thymol. No statistically significant difference was observed between the experimental groups ( $n=10$; ANOVA and Tukey's Test; $P \leq .05$ ).

membrane and affects the integrity of this cell structure, due to the lipophilic characteristic presented by this plant molecule (Cristani et al., 2007). The permeability is facilitated by the presence of hydroxyl group $(\mathrm{OH})$ in the phytocompound, which acts as a transmembrane carrier of monovalent cations, responsible for cell development (Ben Arfa, Combes, Preziosi-Belloy, Gonterd, \& Chalier, 2006; Ultee, Kets, \& Smid, 1999). Thymol can release lipopolysaccharides, due to membrane disintegration, leading to an increase in the levels of extracellular ATP, as well as a decrease in the levels of intracellular ATP (Helander et al., 1998); thus, its ability to inhibit the action of ATPase was also reported (Gill \& Holley, 2006).

Thymol causes morphological changes and alterations in the surface of $C$. albicans, resulting in decrease of adhesion to the substrate (Braga, Alfieri, Culici, \& Dal Sasso, 2007). It can also affect the generation of hyphae (Braga, Sasso, Culici, \& Alfieri, 2007) and inhibit the formation and development of biofilms (Dalleau et al., 2008). Besides interferences in the initial phase of biofilm, thymol can also be effective on mature biofilms, as demonstrated in our study, due to capacity of affecting the metabolism of $C$. albicans in these communities (Braga, Sasso, et al., 2007).

As demonstrated in this study, thymol presented action on $S$. aureus, however its effect on methicillin-resistant staphylococci was also reported, presenting MIC of $128 \mathrm{mg} / \mathrm{mL}$ (Qiu et al., 2010). Additionally, these authors verified that the phytocompound attenuated the hemolytic activity of $S$. aureus, by inhibition of hemolysins.

In this study, $S$. mutans was the most resistant strain to the thymol, showing MIC of $1.06 \mathrm{mmol} / \mathrm{L}$, although inhibition and elimination of $S$. mutans were observed with use of this concentration. Thymol has
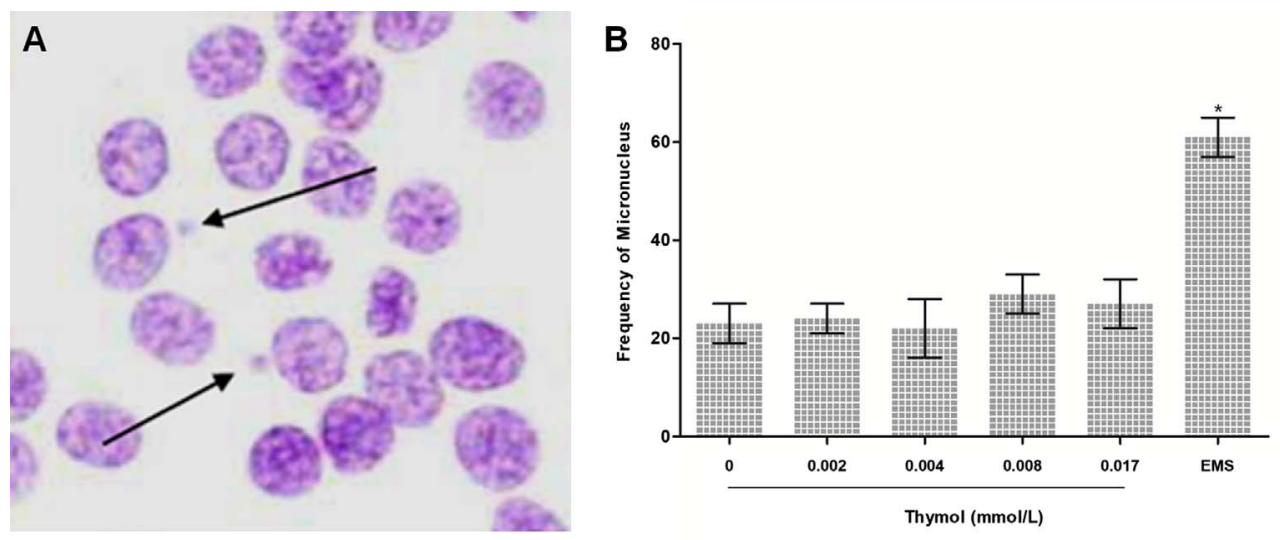

Fig. 4. Genotoxicity of thymol analyzed on murine macrophages (RAW 264.7). (A) By SCHIFF, it was possible to visualize micronuclei separated from the main nucleus however close to it (arrow). (B) Graphic demonstration of mean values ( \pm standard deviation) of the frequency of micronuclei. "Frequency was significantly higher in relation to the experimental groups $(n=2$; ANOVA and Tukey's Test; $P \leq .05$ ). 
showed equivalent effect to ampicillin against $S$. mutans, reaching MIC of $12 \mu \mathrm{g} / \mathrm{mL}$ and $4 \mu \mathrm{g} / \mathrm{mL}$, respectively (Mathela, Singh, \& Gupta, 2010). Therefore, the use of plant products, such as phytocompounds, has a possibility of being an effective alternative to control microorganisms, if any resistance to the routine antimicrobials occurs.

Action of thymol in biofilms was also found in this study. Mean reductions of $20 \%$ (C. albicans and S. aureus) and $25 \%$ (S. mutans) were observed after treatment (Fig. 1). Antibiofilm activity of this phytocompound has also been reported in: biofilm of C. albicans (Braga, Alfieri, et al., 2007); monomicrobial biofilm of $S$. aureus (Nostro et al., 2007) and in association with Listeria monocytogenes (Lebert, Leroy, \& Talon, 2007); monomicrobial biofilm of $S$. mutans (Khan et al., 2017) and in association with Lactobacillus plantarum (Filoche et al., 2005).

Thymol has aided macrophages (RAW 264.7) in the control of in vitro infections, being reported the improvement of the process of phagocytosis against $S$. aureus, as well as the immunoregulation of cytokines and nitric oxide, in infections by $C$. albicans, $S$. aureus, and $P$. aeruginosa (de Oliveira et al., 2017).

Regarding the cytotoxicity, a significant decrease in the viability of RAW 264.7 was observed between 0.07 and $1.06 \mathrm{mmol} / \mathrm{L}$, presenting indices below 50\%. Additionally, reductions at 0.002 and $0.03 \mathrm{mmol} /$ $\mathrm{mL}$ occurred, however the cell viability remained above $50 \%$ (Fig. 2C). These decreases are possibly related to action of the plant product on the cell membrane of the macrophages, since thymol can affect the integrity of this structure in prokaryotic and eukaryotic cells (Gutiérrez et al., 2010). On the other hand, thymol could act as an alternative product for control of tumor cells, including THP-1 (from acute monocytic leukemia) (Ocaña-Fuentes, Arranz-Gutiérrez, Señorans, \& Reglero, 2010); HEp-2 (from human laryngeal carcinoma) (Hsu et al., 2011); HL-60 (from human promyelocytic leukemia) (Deb, Parimala, Saravana Devi, \& Chakraborty, 2011); and Caco-2 (from human epithelial colorectal adenocarcinoma) (Llana-Ruiz-Cabello et al., 2014).

The possible stimulus to production of TNF- $\alpha$ by the macrophages after contact with thymol was checked in this study. In this regard, a similar production of TNF- $\alpha$ was observed at the basal level, after exposure to the phytocompound, demonstrating the possibility of being used to control inflammatory processes. Similarly, the inhibitory effect of the thymol was described on the production of TNF- $\alpha$ (Liang et al., 2014) and interleukin-1 $\beta$ (Chauhan, Jakhar, Paul, \& Kang, 2014).

Genotoxic effect of thymol was also investigated in this study. The analysis showed that the frequency of micronuclei was similar between groups exposed to the phytocompound and control group, demonstrating no DNA damage. Additionally, the plant product was statistically different of the genotoxic agent (EMS), evidencing its absence of genotoxicity. This antimutagenic effect of thymol was also reported on V79 cells (from hamster lung fibroblasts) (Undeğer, Başaran, Degen, \& Başaran, 2009) and Caco-2 cells (Llana-Ruiz-Cabello et al., 2014).

The pharmacological potential of a plant product (thymol) was demonstrated in the present study, including action in planktonic cultures and biofilms of species responsible for relevant infections. Additionally, this product promoted decrease of cell viability in some concentrations, which in this case, could be suitable for application in tumor cells. Thymol showed potential as an immunoregulatory agent, due to absence of stimulus to production of TNF- $\alpha$ by the macrophages. Non-mutagenic activity was another positive effect of thymol. Thus, thymol presented the possibility of being an alternative agent to control infections and tumor cells by means of its addition in therapeutic products.

\section{Conclusion}

Thymol inhibited and eliminated C. albicans, S. aureus, and S. mutans in planktonic cultures and its more effective concentration provided significant reductions of biofilms. Absence of cytotoxicity was observed in some concentrations. Production of TNF- $\alpha$ by the macrophages was similar to the basal level of cells, in more viable concentrations. These viable concentrations also presented antimutagenic effect.

\section{Conflict of interest}

None.

\section{Funding}

This research did not receive any specific grant from funding agencies in the public, commercial, or not-for-profit sectors.

\section{References}

Ben Arfa, A., Combes, S., Preziosi-Belloy, L., Gonterd, N., \& Chalier, P. (2006). Antimicrobial activity of carvacrol related to its chemical structure. Letters in Applied Microbiology, 43, 149-154.

Braga, P. C., Alfieri, M., Culici, M., \& Dal Sasso, M. (2007). Inhibitory activity of thymol against the formation and viability of Candida albicans hyphae. Mycoses, 50, 502-506.

Braga, P. C., Sasso, M. D., Culici, M., \& Alfieri, M. (2007). Eugenol and thymol, alone or in combination, induce morphological alterations in the envelope of Candida albicans. Fitoterapia, 78, 396-400.

Braga, L. C., Shupp, J. W., Cummings, C., Jett, M., Takahashi, J. A., Carmo, L. S., et al. (2005). Pomegranate extract inhibits Staphylococcus aureus growth and subsequent enterotoxin production. Journal of Ethnopharmacology, 96, 355-359.

Bürgers, R., Witecy, C., Hahnel, S., \& Gosau, M. (2012). The effect of various topical periimplantitis antiseptics on Staphylococcus epidermidis, Candida albicans, and Streptococcus sanguinis. Archives of Oral Biology, 57, 940-947.

Burris, K. P., Davidson, P. M., Stewart, C. N., Jr., \& Harte, F. M. (2011). Antimicrobial activity of Yerba Mate (Ilex paraguariensis) aqueous extracts against Escherichia coli O157:H7 and Staphylococcus aureus. Journal of Food Science, 76, M456-M462.

Camargo, C. H., Camargo, S. E., Valera, M. C., Hiller, K. A., Schmalz, G., \& Schweikl, H. (2009). The induction of cytotoxicity, oxidative stress, and genotoxicity by root canal sealers in mammalian cells. Oral Surgery, Oral Medicine, Oral Pathology, Oral Radiology, 108, 952-960.

Chauhan, A. K., Jakhar, R., Paul, S., \& Kang, S. C. (2014). Potentiation of macrophage activity by thymol through augmenting phagocytosis. International Immunopharmacology, 18, 340-346.

CLSI (2002). Reference method for broth dilution in tests for determining the sensitivity to antifungal therapy of yeast. Approved standard, NCCLS document M27-A2 (2nd ed.). USA.

CLSI (2003). Methods for dilution antimicrobial susceptibility tests for bacteria that grow aerobically. Approved standard, NCCLS document M7-A6 (6th ed.). USA.

CLSI (2012). Reference method for broth dilution antifungal susceptibility testing of yeasts. Fourth Informational Supplement M27-S4. USA.

Cristani, M., d'Arrigo, M., Mandalari, G., Castelli, F., Sarpietro, M. G., Micieli, D., et al. (2007). Interaction of four monoterpenes contained in essential oils with model membranes: Implications for their antibacterial activity. Journal of Agricultural and Food Chemistry, 55, 6300-6308.

Dalleau, S., Cateau, E., Bergès, T., Berjeaud, J. M., \& Imbert, C. (2008). In vitro activity of terpenes against Candida biofilms. International Journal of Antimicrobial Agents, 31, 572-576.

de Castro, R. D., de Souza, T. M., Bezerra, L. M., Ferreira, G. L., Costa, E. M., \& Cavalcanti, A. L. (2015). Antifungal activity and mode of action of thymol and its synergism with nystatin against Candida species involved with infections in the oral cavity: An in vitro study. BMC Complementary and Alternative Medicine, 15, 417.

de Oliveira, J. R., Figueira, L. W., Sper, F. L., Meccatti, V. M., Camargo, S. E. A., \& de Oliveira, L. D. (2017). Thymus vulgaris L. and thymol assist murine macrophages (RAW 264.7) in the control of in vitro infections by Staphylococcus aureus, Pseudomonas aeruginosa, and Candida albicans. Immunologic Research, 65, 932-943.

de Oliveira, C. E., Stamford, T. L., Gomes Neto, N. J., \& de Souza, E. L. (2010). Inhibition of Staphylococcus aureus in broth and meat broth using synergies of phenolics and organic acids. International Journal of Food Microbiology, 137, 312-316.

de Vasconcelos, L. C., Sampaio, F. C., de Albuquerque, A. J., \& Vasconcelos, L. C. (2014). Cell viability of Candida albicans against the antifungal activity of thymol. Brazilian Dental Journal, 25, 277-281.

Deb, D. D., Parimala, G., Saravana Devi, S., \& Chakraborty, T. (2011). Effect of thymol on peripheral blood mononuclear cell PBMC and acute promyelotic cancer cell line HL60. Chemico-Biological Interactions - Journal, 193, 97-106.

Faria, N. C., Kim, J. H., Gonçalves, L. A., Martins, M. de L., Chan, K. L., \& Campbell, B. C. (2011). Enhanced activity of antifungal drugs using natural phenolics against yeast strains of Candida and Cryptococcus. Letters in Applied Microbiology, 52, 506-513.

Filoche, S. K., Soma, K., \& Sissons, C. H. (2005). Antimicrobial effects of essential oils in combination with chlorhexidine digluconate. Oral Microbiology and Immunology, 20, $221-225$.

Fratini, F., Casella, S., Leonardi, M., Pisseri, F., Ebani, V. V., Pistelli, L., et al. (2014). Antibacterial activity of essential oils, their blends and mixtures of their main constituents against some strains supporting livestock mastitis. Fitoterapia, 96, 1-7.

Fu, J., Wei, P., Zhao, C., He, C., Yan, Z., \& Hua, H. (2014). In vitro antifungal effect and inhibitory activity on biofilm formation of seven commercial mouthwashes. Oral Diseases, 20, 815-820. 
Gaysinsky, S., Taylor, T. M., Davidson, P. M., Bruce, B. D., \& Weiss, J. (2007). Antimicrobial efficacy of eugenol microemulsions in milk against Listeria monocytogenes and Escherichia coli 0157:H7. Journal of Food Protection, 70, 2631-2637.

Gill, A. O., \& Holley, R. A. (2006). Inhibition of membrane bound ATPases of Escherichia coli and Listeria monocytogenes by plant oil aromatics. International Journal of Food Microbiology, 111, 170-174.

Guo, N., Liu, J., Wu, X., Bi, X., Meng, R., Wang, X., et al. (2009). Antifungal activity of thymol against clinical isolates of fluconazole-sensitive and -resistant Candida albicans. Journal of Medical Microbiology, 58, 1074-1079.

Gutiérrez, L., Batlle, R., Sánchez, C., \& Nerín, C. (2010). New approach to study the mechanism of antimicrobial protection of an active packaging. Foodborne Pathogens and Disease, 7, 1063-1069.

Hammer, K. A., \& Heel, K. A. (2012). Use of multiparameter flow cytometry to determine the effects of monoterpenoids and phenylpropanoids on membrane polarity and permeability in Staphylococci and Enterococci. International Journal of Antimicrobial Agents, 40, 239-245.

Helander, I. M., Alakomi, H. L., Latva-Kala, K., Mattila-Sandholm, T., Pol, I., Smid, E. J., et al. (1998). Characterization of the action of selected essential oil components on Gram-negative bacteria. Journal of Agricultural and Food Chemistry, 46, 3590-3595.

Hsu, S. S., Lin, K. L., Chou, C. T., Chiang, A. J., Liang, W. Z., \& Chang, H. T. (2011). Effect of thymol on $\mathrm{Ca}_{2}{ }^{+}$homeostasis and viability in human glioblastoma cells. European Journal of Pharmacology, 670, 85-91.

Jentsch, H. F., Eckert, F. R., Eschrich, K., Stratul, S. I., \& Kneist, S. (2014). Antibacterial action of chlorhexidine/thymol containing varnishes in vitro and in vivo. International Journal of Dental Hygiene, 12, 168-173.

Khan, S. T., Khan, M., Ahmad, J., Wahab, R., Abd-Elkader, O. H., Musarrat, J., et al. (2017). Thymol and carvacrol induce autolysis, stress, growth inhibition and reduce the biofilm formation by Streptococcus mutans. AMB Express, 7, 49.

Koziel, R., Szczepanowska, J., Magalska, A., Piwocka, K., Duszynski, J., \& Zablocki, K. (2008). Ciprofloxacin inhibits proliferation and promotes generation of aneuploidy in Jurkat cells. Proteomics, 8, 2936-2947.

La Storia, A., Ercolini, D., Marinello, F., Di Pasqua, R., Villani, F., \& Mauriello, F. (2011). Atomic force microscopy analysis shows surface structure changes in carvacroltreated bacterial cells. Research in Microbiology, 162, 164-172.

Lebert, I., Leroy, S., \& Talon, R. (2007). Effect of industrial and natural biocides on spoilage, pathogenic and technological strains grown in biofilm. Food Microbiology, 24, 281-287.

Liang, D., Li, F., Fu, Y., Cao, Y., Song, X., \& Wang, T. (2014). Thymol inhibits LPS-stimulated inflammatory response via down-regulation of NF- $\mathrm{kB}$ and MAPK signaling pathways in mouse mammary epithelial cells. Inflammation, 37, 214-222.

Llana-Ruiz-Cabello, M., Gutiérrez-Praena, D., Pichardo, S., Moreno, F. J., Bermúdez, J. M., \& Aucejo, S. (2014). Cytotoxicity and morphological effects induced by carvacrol and thymol on the human cell line Caco-2. Food and Chemical Toxicology, 64, $281-290$

Mathela, C. S., Singh, K. K., \& Gupta, V. K. (2010). Synthesis and in vitro antibacterial activity of thymol and carvacrol derivatives. Acta Poloniae Pharmaceutica, 67, $375-380$.

Nostro, A., Sudano Roccaro, A., Bisignano, G., Marino, A., Cannatelli, M. A., Pizzimenti, F. C., et al. (2007). Effects of oregano, carvacrol and thymol on Staphylococcus aureus and Staphylococcus epidermidis biofilms. Journal of Medical Microbiology, 56, 519-523.

Ocaña-Fuentes, A., Arranz-Gutiérrez, E., Señorans, F. J., \& Reglero, G. (2010) Supercritical fluid extraction of oregano (Origanum vulgare) essentials oils: Anti-inflammatory properties based on cytokine response on THP-1 macrophages. Food and Chemical Toxicology, 48, 1568-1575.

Oliveira, J. R., Viegas, D. J., Martins, A. P. R., Carvalho, C. A. T., Soares, C. P., Camargo, S. E. A., et al. (2017). Thymus vulgaris L. extract has antimicrobial and anti-inflammatory effects in the absence of cytotoxicity and genotoxicity. Archives of Oral Biology, 82, 271-279.

Paula, V. A., Modesto, A., Santos, K. R., \& Gleiser, R. (2010). Antimicrobial effects of the combination of chlorhexidine and xylitol. British Dental Journal, 209, E19.

Pereira, V., Lopes, C., Castro, A., Silva, J., Gibbs, P., \& Teixeira, P. (2009). Characterization for enterotoxin production, virulence factors, and antibiotic susceptibility of Staphylococcus aureus isolates from various foods in Portugal. Food Microbiology, 26, 278-282.

Qiu, J., Wang, D., Xiang, H., Feng, H., Jiang, Y., Xia, L., et al, (2010). Subinhibitory concentrations of thymol reduce enterotoxins A and B and alpha-hemolysin production in Staphylococcus aureus isolates. PLoS ONE, 5, e9736.

Rúa, J., Fernández-Alvarez, L., Gutiérrez-Larraínzar, M., del Valle, P., de Arriaga, D., \& García-Armesto, M. R. (2010). Screening of phenolic antioxidants for their inhibitory activity against foodborne Staphylococcus aureus strains. Foodborne Pathogens and Disease, 7, 695-705.

Seneviratne, C. J., Wang, Y., Jin, L., Abiko, Y., \& Samaranayake, L. P. (2010). Candida albicans biofilm formation is associated with increased anti-oxidative capacities. Journal of Physiology and Pharmacology, 61, 233-239.

Sharifzadeh, A., Khosravi, A. R., Shokri, H., \& Sharafi, G. (2015). Antifungal effect of Trachyspermum ammi against susceptible and fluconazole-resistant strains of Candida albicans. Journal de Mycologie Médicale, 25, 143-150.

Stammati, A., Bonsi, P., Zucco, F., Moezelaar, R., Alakomi, H. L., \& von Wright, A. (1999). Toxicity of selected plant volatiles in microbial and mammalian short-term assays. Food and Chemical Toxicology, 37, 813-823.

Ultee, A., Kets, E. P. W., \& Smid, E. J. (1999). Mechanisms of action of carvacrol on the food-borne pathogen Bacillus cereus. Applied and Environmental Microbiology, 65, 4606-4610.

Undeğer, U., Başaran, A., Degen, G. H., \& Başaran, N. (2009). Antioxidant activities of major thyme ingredients and lack of (oxidative) DNA damage in V79 Chinese hamster lung fibroblast cells at low levels of carvacrol and thymol. Food and Chemical Toxicology, 47, 2037-2043.

Veras, H. N., Rodrigues, F. F., Colares, A. V., Menezes, I. R., Coutinho, H. D., Botelho, M. A., et al. (2012). Synergistic antibiotic activity of volatile compounds from the essential oil of Lippia sidoides and thymol. Fitoterapia, 83, 508-512. 